\title{
Patients with Chronic Venous Insufficiency: Treatment Modalites of Venous Impairment and Its Complications during Two Years Period in Primary Care Center
}

\author{
Zeynep Gökalp Çevik \\ Ihlamurkent Family and Children Health Center, Eskisehir, Turkey \\ Email: zeynepgokalpmd@yahoo.com
}

Received 29 July 2015; accepted 18 August 2015; published 21 August 2015

Copyright (C) 2015 by author and OALib.

This work is licensed under the Creative Commons Attribution International License (CC BY). http://creativecommons.org/licenses/by/4.0/

(c) (i) Open Access

\section{Abstract}

Background: Venous disease is a common health problem in developed countries. The aim of this study was to research the medical treatment strategy, complication due to venous impairment including leg ulcer, deep and/or superficial phlebothrombosis related to chronic venous insufficiency (CVI) two years follow-up. Patients and Methods: This prospective study has been planned in our Family and Children Health Center. 196 patients who have CVI have been included for the study. The mean age of these patients was $45.0 \pm 12.4$ y (17 - $80 \mathrm{y})$. One hundred patients were female and the remaining 96 patients were male. The main complaints of the patients were leg pain, visible varices, skin hyperpigmentation and leg edema. Twenty-eight patients were hypertensive and 22 were diabetics. Cardiovascular specialists did recommend a mikronize flavonoid fractions, calcium dobesilat or oxerutine as a medical treatment. Also, compression bandage or stockings have been recommended additionally. Results: During two years period, leg ulcer developed in 10 patients ( 7 female and 3 male). Deep venous thrombosis has been detected by doppler USG in these patients who used antiaggregant and anticoagulants. We also detected deep venous thrombosis in two pregnant women. Control doppler ultrasonography showed that venous regurgitation increased from grade I to grade III or IV in 44 patients ( 33 female, 11 male; $p<0.05$ ). Superficial venous thrombotic events related to CVI have been detected in nine patients. Dermatotrophyc changes and deep venous disease were common in women (OR $=0.7$ for both) $(p=$ 0.0032). Visible varicose veins were closely linked; $87.3 \%$ of legs were concordant and $13.7 \%$ discordant. The age-adjusted prevalence of edema, superficial events, and deep events were estimated as $32.2 \%, 19.3 \%$, and $29.6 \%$, respectively, compared with $1.2 \%, 0.3 \%$, and $1.1 \%$ for legs visibly and functionally normal. Conclusion: Our study results showed that CVI complications and its complaints are more common in females. Complications because of CVI are more common and complaints are more severe in patients who did not use regularly pharmacologic treatment and 
compression stockings. Complications such as venous thrombosis and dermatotrophyc changes due to CVI are common especially in obese females. To decrease leg complaints due to venous stasis and its complication pharmacologic treatment together with compression stockings or bandage use regularly are very important factors.

\title{
Keywords
}

\author{
Chronic Venous Insufficiency, Medications, Leg Complaints, Compression Therapy
}

\author{
Subject Areas: Public Health
}

\section{Introduction}

Varicose veins have an estimated prevalence between 5\% to 30\% in the adult population, with a female to male predominance of 3 to 1. The San Valentino Vascular Screening Project found among the 30,000 subjects evaluated by clinical assessment and duplex ultrasound a prevalence of 7\% for varicose veins and 0.86\% for symptomatic CVI. As in previous studies, CVI was more common with increasing age. Risk factors found to be associated with CVI include age, sex, a family history of varicose veins, obesity, pregnancy, and phlebitis history [1] [2]. There also may be environmental or behavioral factors associated with CVI such as prolonged standing and perhaps a sitting posture at work [3] [4]. Varicose veins have a significant impact on healthcare resources, with millions of people seeking medical attention for their cosmetic appearance annually. Although often minimized, the cosmetic consequences may adversely affect an individual's quality of life and are associated with other manifestations. The clinical symptoms of CVI include heaviness, edema and pain in the affected leg especially at the night. Physical findings include swelling, visible varicose veins, and cuticular hyperpigmentation. Hyperpigmentation is due to the deposits of hemosiderin in the skin by erythrocyte breakdown. In general, patients with CVI develop lipodermatosclerosis of the affected limb. This term describes the progressive replacement of the skin and subcutaneous tissue by fibrous scarring. This dermal change may be mistaken for cellulitis and often precedes the development of a venous ulcer. Ulcerations classically occur along the medial malleolar area of the lower leg. Venous ulcers may occur in other areas, such as the lateral malleolar area and the dorsum of the foot. Patients with CVI, with or without ulceration, also have a higher incidence of stasis and contact dermatitis. Clinical classification starts with no signs of CVI and then considers the presence of varicosities, subcutenous edema, lipodermatosclerosis, and active ulceration. All of these may be determined by physical assessment. The etiologic classification distinguishes between primary and secondary CVI. Patients with a history of phlebitis or trauma would be classified as having secondary CVI.

Thus, because CVI and its complications are more prevalent in our developed country, we investigated the patients' complaints related to CVI, the effect of treatment modalities, and evaluated the risk factors for future events due to venous impairment.

\section{Patients and Methods}

After local ethics committee approved this study, the patients' consent and signature has been given. 196 patients who admitted to our center, have been included for the study. Our research has been completed by primary care physician and Integrated Government Hospital. All patients have admitted to out-patients clinic because of leg pain, early fatigue during walking, visible varices, leg edema and hyperpigmentation. Patients with CVI have diagnosed by a radiologist. Medical treatment has been recommended by the cardiovascular surgeon. The patients' demographics including profession, occupation, and systemic disease such as hypertension or diabetes have been summarised in Table 1. We prepared a special form including 19 questions for this research. Experienced nurses have filled the form including the degree of patients' complaints, the kind of treatments, tradition of bandage or stockings use, etc. This form included the degree of complaints during use of compression therapy, tenderness, edema, hyperpigmentation, history of surgery or venous ulcer, patients' education, and sosyo-economic properties. 
Table 1. Demographycs, socio-cultural and education data of the patients.

\begin{tabular}{lcc}
\hline Socio-Demographic Properties & Number & $\%$ \\
\hline Gender & 100 & 51.9 \\
Female & 96 & 48.1 \\
Male & & \\
Occupation & 67 & 33.2 \\
Housewives & 83 & 41.6 \\
Long Standing Profession & 56 & 17,5 \\
Office worker & & \\
Education & 44 & 24.6 \\
No any & 52 & 26 \\
Primary School & 88 & 44.6 \\
College & 16 & 32 \\
University & & 12 \\
Smoker & 156 & 78 \\
No & 44 & 22 \\
Yes & 24 & \\
Alchool & 36 & 11 \\
No & & \\
Egsersize & 28 & \\
Yes & & \\
Hypertension & & \\
Diabetes & & \\
\hline & & \\
\hline
\end{tabular}

The mean age of the patient was $45.0 \pm 12.4$ years (17 - $80 \mathrm{y}$ ). The mean age of the male and female patients was $46.5 \pm 9.4 \mathrm{y}$ and $43.7 \pm 13.6 \mathrm{y}$. There was nostatistical significance $(\mathrm{p}=0.086)$. Our results have showed that the severity of complaints due to CVI were more common in females. This result showed that pregnancy and hormonal differences in both genders could be important factors. Our investigation demonstrated that patients' education was low in females with CVI. Leg pain, skin edema and early fatique were more severe in female group $(p=0.020)$. Education degree was higher and complaints was low in male patients $(p=0.004)$. Because International Classification of Primary Care (ICPC-II) classifies patient data and clinical activity in domains of general family practices and primary care, we used ICPC-II classification for these patients. The patients' complaints and ICPC-II properties have been summarized in Table 2.

\section{Statistical Analyses}

All statistical analyses were performed using the SPSS statistical software (SPSS for Windows 15.0, Inc., Chicago, IL, USA). Normally distributed continuous variables were expressed as mean values \pm standard deviation (SD). Categorical variables were expressed as numbers and percentages. Demographic characteristics was compared using independent samples t-test. Chi-square or Fisher's exact test was used for categorical variables. Within-group differences were evaluated with the paired-samples t-test. A p value $<0.05$ was considered statistically significant.

\section{Results}

In all patients, doppler ultrasonography has been performed and venous incompetence has been reported. According to the USG results, there were no any significance differences when compared to venous impairment 


\begin{tabular}{|c|c|c|}
\hline Complaints & Number (\%) & ICPC-II Classification \\
\hline \multicolumn{3}{|l|}{ Leg pain } \\
\hline Female & $100(100)$ & L14 \\
\hline Male & $96(100)$ & L14 \\
\hline \multicolumn{3}{|l|}{ Edema* } \\
\hline Female & $78(78)$ & L14 \\
\hline Male & $64(66)$ & L14 \\
\hline \multicolumn{3}{|c|}{ Muscle Cramp* } \\
\hline Female & $64(64)$ & L14 \\
\hline Male & $44(40)$ & L14 \\
\hline \multicolumn{3}{|c|}{ Discomphort food ${ }^{*}$} \\
\hline Female & $85(85)$ & L17 \\
\hline Male & $36(41)$ & L17 \\
\hline \multicolumn{3}{|l|}{ Early fatique $^{*}$} \\
\hline Female & $53(53)$ & L17 \\
\hline Male & 27 (26.7) & L17 \\
\hline \multicolumn{3}{|c|}{ Hyperpigmetation ${ }^{*}$} \\
\hline Female & $29(29)$ & S08 \\
\hline Male & $11(10.04)$ & S08 \\
\hline \multicolumn{3}{|c|}{ Egsematos change $^{*}$} \\
\hline Female & $43(43)$ & \\
\hline Male & $12(18)$ & \\
\hline \multicolumn{3}{|c|}{ Sensation disorder ${ }^{*}$} \\
\hline Female & $49(49)$ & N06 \\
\hline Male & $22(19.8)$ & N06 \\
\hline
\end{tabular}

$$
{ }^{*} \mathrm{p}=0.05
$$

grades. Sapheno-femoral valve incompetence was similar in all patients (grade 1 - 2). We detected leg pain, edema and tenderness as main complaints in both gender. According to the forms, pain during long standing and leg discomphort were more severe in females then males $(p=0.022)$. Affected leg pain, muscular cramp and prevalance of edema have detected in $64 \%$ and $78 \%$ of females, respectively. These were statistically significant (Table 2). Hyperpigmentation and egzematous skin changes have been detected in $29 \%$ and $43 \%$ of females, respectively (Table 2). Sensation disorder and early fatique during walking are more prevalant in female patients.

According to ICPC-II classification leg discomphort and tenderness were more common in female cases. These were statistical significance $(p=0.001)$. In older male and female patients we detected severe muscular cramp at the end of day. Accelerated varicosities bilaterally were common when they did not use prescribed drugs and compression stockings regularly in both gender. Our study results have also showed the profession or occupation of patients have affected these symptoms. There was no any severe symptom in patients who used compression stockings or bandage and drug use regularly. The degree of venous failure was parallel to leg symptoms in young housewife patients and pregnants. 24 patients (15 females and 9 males) did not use antiva- 
rices drug. 44 patients (19 females and 25 males) have used regularly Mikronised flavonoid extraction. Calsium dobesilat has prescribed for $31.3 \%$ of patients (44 males and 20 females). A small number of patients received oxerutine (5.6\%). Anticoagulant/antiplatelet has been prescribed for superficial thrombophlebitis. Combination treatment has been suggested in 49 patients (24.9\%). 99 patients could not use regularly compression stockings or bandage. Medication of the patients have been summarized in Table 3. The patients described the difficulties of stockings and bandage use. The main reasons were irritation of legs, sweating, and over tightening. Compression bandage or stockings use in patients have been summarized in Table 4.

During two years follow-up 82 patients required surgical treatment (stripping, high ligation of saphenous vein, endovenous laser, etc.) under spinal or local anaesthesia in hospital. 70 of 82 patients did not visit our primary care physician center for controlling. We detected that socio-demographics and educations' properties was strongly related to control visiting by family doctor. Prescribed drug and compression stocking use were lower in these patients $(\mathrm{OR}=38.20 ; \mathrm{p}=0.001)$. Housewife patients did not use regularly recommended compression stockings $(\mathrm{OR}=26.10 ; \mathrm{p}=0.001)$. Resulting from these low education and occupation problems leg complaints related to CVI increased in these particular patients $(\mathrm{OR}=36.32 ; \mathrm{p}=0.01)$.

During follow-up, we deteceted leg ulcerin 5 patients (2 females and 3 males). Deep venous thrombosis in eight patients ( 5 females and 2 males). Superficial thrombophlebitis has been diagnosed in 9 patients (seven females and two males). Complications are showed in Figure 1. Leg ulcer as an important complication has been detected in a male patient who have deep venous thrombosis (Figure 2). Bilateral leg hyperpigmentation has been detected as another complication (Figure 3).

Antibiotics. leg elevation, and compression bandage have been used after patients hospitalisation. Symptomatic deep venous thrombosis in two female patients has been detected during the pregnancy period (in the second trimester). Low molecular weight heparin and antiplatelet treatment have been given. History of these two females showed they did not use compression stockings or bandage and leg elevation after CVI diagnosis. Control doppler USG clearly showed that venous regurgitation increased from grade 1 to 3 or 4 in 15 patients at

\begin{tabular}{cc} 
Table 3. Medications for treatment. \\
\hline Drug & Number (\%) \\
\hline No drug use & $24(12)$ \\
Mikronised flavonoid extraction & $44(23.6)$ \\
Calsium dobesilat & $64(31.3)$ \\
Oxerutine & $11(5.6)$ \\
Anticoagulant/antiplatelet & $8(3.7)$ \\
Combination treatment & $49(24.9)$ \\
\hline
\end{tabular}

\begin{tabular}{lcc} 
Table 4. Compression bandage or stockings. & & \\
\hline & Number & $\%$ \\
\hline No use & 99 & 47.6 \\
Regular use & 52 & 26.5 \\
Irregular use & 45 & 22.1 \\
Complaints related to compression bandage or stockings & & \\
No complaint & 34 & 47.4 \\
Over tightening & 44 & 46.3 \\
Sweat & 13 & 5.5 \\
Irritation & 6 & 3.1 \\
Difficulity in use & 7 & 3.2 \\
\hline
\end{tabular}




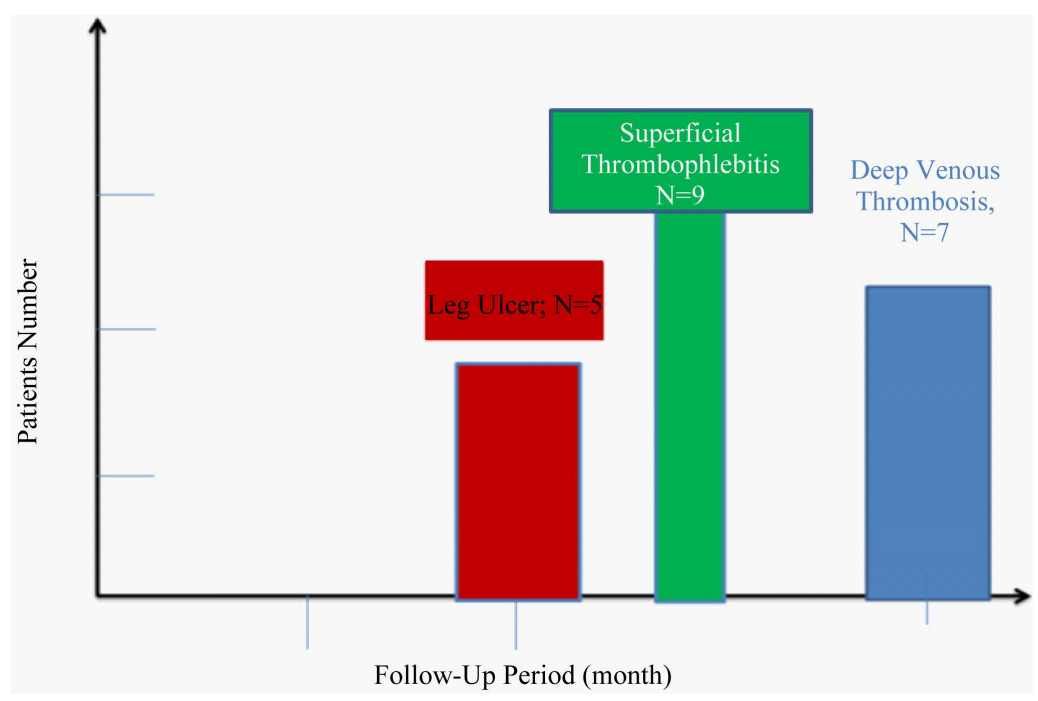

Figure 1. Shows the number of patients who havecomplications of CVI in patients.

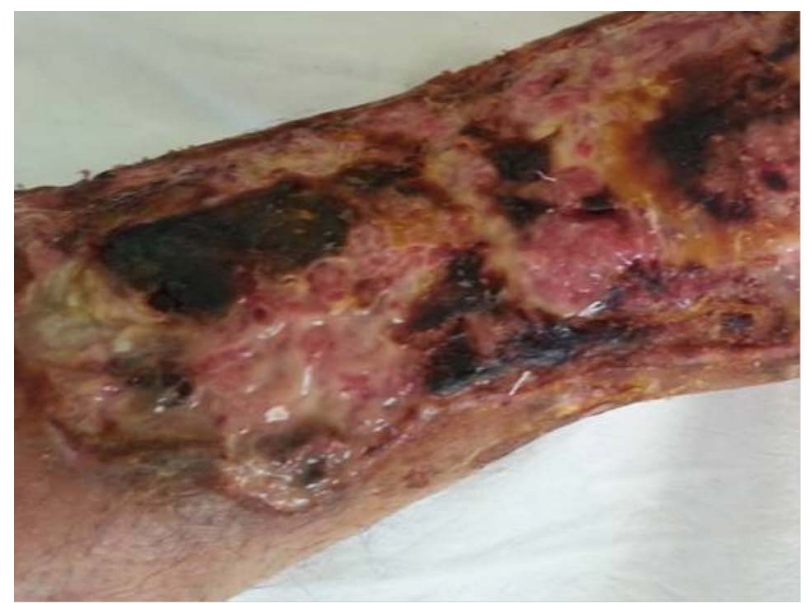

Figure 2. Demonstrates severe infected leg ulcer as a complication of CVI after deep venous thrombosis in an older male.

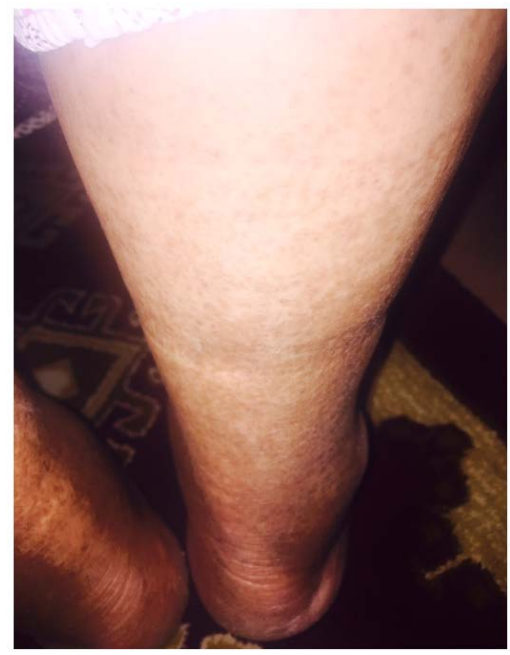

Figure 3. Exhibites that bilateral hyperpigmentation in an obese female. 
the end of follow-up period. These complications have more prevalent in female patients (p $=0.001)$. Superficial venous disease and superficial thrombotic events related to venous disease were more common in obese females than men (odds ratio $(\mathrm{OR})=3.8, \mathrm{OR}=1.8(\mathrm{p}<0.05)$. Severe trophyc changes and deep functional disease were also common in women $(p=0.0032)$. Visible varicose veins and functional (superficial or deep) disease were closely linked; $87.3 \%$ of legs were concordant and $13.7 \%$ discordant. The age-adjusted prevalences of edema, superficial events, and deep events were estimated as 32.2\%, 19.3\%, and 29.6\%, respectively, compared with $1.2 \%, 0.3 \%$, and $1.1 \%$ for legs visibly and functionally normal.

\section{Discussion}

Chronic venous disease is a common disorder that affects the veins of the legs in developed country. These veins carry blood from the legs to the heart. Normal veins have a series of valves that open and close to direct blood flow from the surface of the legs to the deep leg veins, from which calf muscles pump blood back to the heart; the valves also control the pressure in smaller veins on the legs' surface. Our study clearly shows that CVI diagnosis can be done clearly using a doppler ultrasonography as a non-invasive tool, and suitable treatment modalities are the most important factors for treatment. To prevent CVI and its complications the other important factors are diets, regular egsersize, leg elevation, compression stockings and drug use. In assessing a patient with venous disorders including leg ulcer, a differential diagnosis should be research. The typicalvenous ulcer presents as a painful lower leg lesion, associated with hyperpigmentation and lipodermatosclerosis [5]-[7]. However, an estimated $15 \%$ - 20\% of patients with a venous ulcer have associated arterial insufficiency [8]-[11]. Palpation of the pedal artery can be difficult in these patients. The recognition of an arterial component to a venous ulcer is essential [12]-[14].

Compression therapy, critical in treating CVI, can have disastrous results if compression pressures exceed arterial pressures [15]. The presence of squamous cell or basal cell carcinoma in a classic venous ulcer has been described many times [16]. For ulcers of long-standing duration (>6 months) or ulcers that do not respond promptly to therapy, a biopsy specimen should be examined to confirm the diagnosis. Vasculitic ulcers associated with underlying connective tissue or immune system disorders may be misdiagnosed as venous ulcers. Biopsy specimens from the edge of the ulcer may reveal the presence of vasculitis [17].

The appearance of venous ulcers in patients with CVI has been attributed to elevated venous pressures as a result of venous valvular incompetence, deep venous obstruction, or a combination of both [18]-[20]. Venous reflux in multiple segments of both the deep and superficial venous systems was associated with CVI and ulceration. Indeed, venous ulcer developed during the study period in our patients. In these patients venous reflux in the deep and superficial systems below the knee leads to calf pump failure. Also, control doppler USG showed that venous pressures increased in the lower leg in our particular patients. Our ultrasonographyc studies exhibited that in 36 patient, 24 females and 12 males, the tissue below the knee was therefore exposed to elevated venous pressures continually when the legs are dependent.

It is unclear, however, why elevated venous pressures lead to venous ulcers. Edema secondary to higher venous pressure can be a factor. 11 patients have had diagnosed congestive heart failure and associated bilateral limb edema do not develop the skin changes and ulcerations typical of venous stasis disease.

Recent studies showed that diuretics are probably the most commonly used drugs in the treatment of CVI and the edema associated with venous ulceration [21]-[23]. Diuretics may help mobilize fluid in conjunction with aggressive compression therapy, but they are ineffective if given alone for edema control. But, we did not use any diuretics except in patients with congestive heart failure.

We prescribed hemorheologic and venotonic agents such as micronised flavonoids or calcium dobesilat in various trials in the treatment of venous ulceration in attempts to alter the microcirculation in patients with CVI. In a multicenter study of standard compression therapy and high dosages of venoprotectors, healing was accelerated in the treated group over that in patients receiving compression therapy alone [24]. Many authors have advocated the use of venotonic drugs, such as Daflon, in the treatment of CVI. The drugs are thought to increase venous tone in patients with abnormal venous elasticity and thereby decrease capillary leakage, thus altering the microcirculation [25] [26].

The most effective treatment of CVI and venous ulceration is aggressive leg compression therapy using bandage or compression stockings. According to this concept we have generally used in our patients. The goal of compression therapy is to provide a gradient of pressure from the ankle to the knee or thigh, depending on the 
type of device ordered. Maximum pressure is exerted at the ankle and minimum pressure is exerted at the top of the device. Aggressive compression coapts damaged valve leaflets, lowers capillary pressure, and therefore improves the efficiency of the calf pump. According to the our study compression therapy should be used in pregnant patients. As we know that compression stockings are classified into 4 grades on the basis of the compression exerted at the ankle. Stockings graded at $20-30 \mathrm{mmHg}$ are recommended for patients with varicose veins, mild edema, or leg fatigue. Stockings graded at 30 - 40 mm Hg are useful for treating patients with severe varicosities or moderate CVI. Stockings graded at $40-50 \mathrm{~mm} \mathrm{Hg}$ and $\geq 60 \mathrm{~mm} \mathrm{Hg}$ may be used for patients with severe CVI and its complications. Knee-high stockings are better tolerated by most patients than thigh-high stockings and should be ordered preferentially [27]. The disadvantages associated with stockings include the patient's difficulty in putting them on, especially over bandages like our patients. We saw that this was a major problem for our obese female patients with severe arthritis. Continued use of compression stockings after ulcer healing has been found to lower the incidence of recurrent venous ulceration [28]. In these particular patients we recommended elastic wraps for patients who are unable to wear stockings.

Our some patients who did not use regularly medical treatment required surgery. Surgical procedure for treatment of severe venous impairment was aimed at healing dramatically. In our four patients venous valve repair was done in vascular surgery sections. After the surgical procedures, we saw that symptoms and venous ulcer healed in all patients.

\section{Conclusion}

CVI has been diagnosed in a number of cases with leg complaints who admitted to out-patients clinics. People with chronic venous disease often report that their legs feel heavy, tired, or achy. These problems are more common at the end of the day or after standing for long periods. The feet and ankles may also become swollen. People who have chronic venous disease can develop problems such as skin infections, skin color changes, rashes, or sores that do not heal. These sores, called ulcers, can be difficult to treat, and sometimes take months or years to heal, especially without proper evaluation and treatment. The main complaints are affected leg pain, early fatique during walking, leg edema, hyperpigmentation and visible varices. Our research demonstrated that severe complications can be developed and most expensive treatment can be required during the follow-up period. The treatment strategy of severe clinical condition is usual in both genders. Early diagnosis and treatment modalities are very important by primary care physicians. To prevent this pathology and its severe complications we recommend the patients' loss weight, exercise, and compression therapy. New technologies hold hope for the future, but their cost effectiveness still needs to be determined.

\section{References}

[1] Scott, T.E., LaMorte, W.W., Gorin, D.R. and Menzoian, J.O. (1995) Risk Factors for Chronic Venous İnsufficiency: A Dual Case-Control Study. Journal of Vascular Surgery, 22, 622-628. http://dx.doi.org/10.1016/S0741-5214(95)70050-1

[2] Jawien, A. (2003) The İnfluence of Environmental Factors in Chronic Venous İnsufficiency. Angiology, 54, $19-31$. http://dx.doi.org/10.1177/000331970305400104

[3] Lacroix, P., Aboyans, V., Preux, P.M., Houles, M.B. and Laskar, M. (2003) Epidemiology of Venous İnsufficiency in an Occupational Population. International Angiology, 27, 172-176.

[4] Fowkes, F.G., Evans, C.J. and Lee, A.J. (2001) Prevalence and Risk Factors for Chronic Venous İnsufficiency. Angiology, 52, 5-15. http://dx.doi.org/10.1177/000331970105200102

[5] Callum, M. (1992) Prevalence of Chronic Leg Ulceration and Severe Chronic Venous Disease in Western Countries. Phlebology Suppl, 1, 6-12.

[6] Capeheart, J.K. (1996) Chronic Venous İnsufficiency: A Focus on Prevention of Venous Ulceration. Journal of Wound Ostomy \& Continence Nursing, 23, 227-234. http://dx.doi.org/10.1097/00152192-199607000-00018

[7] Hume, M. (1992) Venous Ulcers, the Vascular Surgeon, and the Medicare Budget. Journal of Vascular Surgery, 16, 671-673. http://dx.doi.org/10.1016/0741-5214(92)90219-X

[8] Cornwall, J.V., Dore, C.J. and Lewis, J.D. (1986) Leg Ulcers: Epidemiology and Aetiology. British Journal of Surgery, 73, 693-696. http://dx.doi.org/10.1002/bjs.1800730905

[9] Baker, S.R., Stacey, M.C., Singh, G., Hoskin, S.E. and Thompson, P.J. (1992) Aetiology of Chronic Leg Ulcers. European Journal of Vascular Surgery, 6, 245-252. http://dx.doi.org/10.1016/S0950-821X(05)80313-5 
[10] Rudolph, D.M. (1998) Pathophysiology and Management of Venous Ulcers. Journal of Wound Ostomy \& Continence Nursing, 25, 248-255. http://dx.doi.org/10.1097/00152192-199809000-00008

[11] Phillips, T., Babette, S., Provan, A. and Lew, R. (1994) A Study of the İmpact of Leg Ulcers on Quality of Life: Financial, Social, and Psychologic İmplications. Journal of the American Academy of Dermatology, 31, 49-53. http://dx.doi.org/10.1016/S0190-9622(94)70134-2

[12] Nelson, O., Bergqvist, D. and Lindhagen, A. (1991) Leg Ulcer Etiology: A Crosssectional Population Study. Journal of Vascular Surgery, 14, 557-564. http://dx.doi.org/10.1016/0741-5214(91)90251-O

[13] Scott, T.E., LaMorte, W.W., Gorin, D.R. and Menzoian, J.O. (1995) Risk Factors for Chronic Venous İnsufficiency: A Dual Case-Control Study. Journal of Vascular Surgery, 22, 622-628. http://dx.doi.org/10.1016/S0741-5214(95)70050-1

[14] Bergqvist, D., Lindholm, C. and Nelzen, O. (1999) Chronic Leg Ulcers: The İmpact of Venous Disease. Journal of Vascular Surgery, 29, 752-755. http://dx.doi.org/10.1016/S0741-5214(99)70330-7

[15] Bryant, R.A., Ed. (1992) Acute and Chronic Wounds. Mosby, St. Louis, 164-204.

[16] Phillips, T. and Dover, J.S. (1991) Leg Ulcers. Journal of the American Academy of Dermatology, 25, 965-987. http://dx.doi.org/10.1016/0190-9622(91)70295-D

[17] Hogan, D.J. and Stewart, M. (1999) Contact Dermatitis: A Precis for Wound Healers. Wounds, 11, 2-10.

[18] Porter, J.M. and Moneta, G.L. (1995) Reporting Standards in Venous Disease: An Update. Journal of Vascular Surgery, 21, 635-645. http://dx.doi.org/10.1016/S0741-5214(95)70195-8

[19] Kistner, R.L. (1997) Classification of Chronic Venous Disease. Vascular and Endovascular Surgery, 31, 217-218. http://dx.doi.org/10.1177/153857449703100302

[20] Baker, J.D. (1995) Lower Extremity Occlusive Disease. In: Ernst, C. and Stanley, J., Eds., Current Therapy in Vascular Surgery, Mosby, New York, 432-440.

[21] Weingarten, M. (1994) Advances in Wound Healing. In: Oloff, L.M., Ed., Musculoskeletal Disorders of the Lower Extremities, W B Saunders, Philadelphia, 52-64.

[22] Weingarten, M.S., Branas, C.C. and Czederarczuk, M. (1993) Distribution and Quantification of Venous Reflux in Lower Extremity Chronic Venous Stasis Disease with Duplex Scanning. Journal of Vascular Surgery, 18, 753-759. http://dx.doi.org/10.1016/0741-5214(93)90328-J

[23] Falanga, V. and Eaglstein, W.H. (1993) The Trap Hypothesis of Venous Ulceration. The Lancet, 341, 1006-1008. http://dx.doi.org/10.1016/0140-6736(93)91085-Z

[24] Stacey, M.C., Burnand, K.G., Bhogal, B.S. and Black, M.M. (2000) Pericapillary Fibrin Deposits and Skin Hypoxia Precede Changes of Lipodermatosclerosis in Limbs at İncreased Risk of Developing a Venous Ulcer. Cardiovascular Surgery, 8, 372-380. http://dx.doi.org/10.1016/S0967-2109(00)00031-4

[25] Smith, P.D.C. (1996) The Microcirculation in Venous Hypertension. Cardiovascular Research, 32, 789-795. http://dx.doi.org/10.1016/S0008-6363(96)00147-2

[26] Takase, S., Bergan, J.J. and Schmid-Schonbein, G. (2000) Expression of Adhesion Molecules and Cytokines on Saphenous Veins in Chronic Venous İnsufficiency. Annals of Vascular Surgery, 14, 427-435. http://dx.doi.org/10.1007/s100169910092

[27] Weingarten, M., Czederarczuk, M., Scovell, S., Branas, C.C., Mignogna, G.M. and Wolferth, C.C. (1996) A Correlation of Air Plethysmography and Color-Flow-Assisted Duplex Scanning in the Quantification of Chronic Venous İnsufficiency. Journal of Vascular Surgery, 24, 750-754. http://dx.doi.org/10.1016/S0741-5214(96)70008-3

[28] Dormandy, J.A. (1995) Pharmacologic Treatment of Venous Leg Ulcers. Journal of Cardiovascular Pharmacology, 25, S61-S65. http://dx.doi.org/10.1097/00005344-199500252-00013 